\section{Lung cancer risk in subjects exposed to organic dust: an unexpected and surprising story}

In a recently published multicentre casecontrol study evaluating lung cancer risk among subjects exposed to organic dusts, ${ }^{1}$ the authors could not confirm the findings from previous reports in which a decreased risk was found among workers in the cotton industry and animal farmers. ${ }^{2}$

Regarding a decreased risk of lung cancer among cotton workers ${ }^{3-7}$ the authors quite rightly concluded that their material was not suitable to evaluate this relationship as their subgroups did not reflect the critical exposure groups, i.e. those exposed to high levels of endotoxin such as cardroom workers and weavers. ${ }^{8}$

For farmers we believe that the multicentre case-control study findings have the same shortcomings for the following reasons. In the Veneto region of Italy, where the first study reporting a decreased risk of lung cancer among farmers was carried out, ${ }^{9}$ the number of farmers has progressively decreased over the last three decades. People leaving dairy farming have taken employment in industries and services in which the exposure level to organic dusts is low. In a cohort of dairy farmers enrolled in this region, the number of active workers in 1998 was 541 of 5634 (9.6\%) workers who reported working in dairy farms sometime during their lifetime. ${ }^{10}$ The results in the cohort study suggest an exposure-dependent reduction in the risk of lung cancer for dairy farmers during the observation period 1970-1984, when most subjects were working on their farms, but not during the period 1985-1998 when they presumably had other occupations. A cohort nested case-control study controlling for age and smoking habits confirmed that recent exposure to dairy farm dust protected against lung cancer while this protective effect was no longer present when more than 15 years had elapsed since working on the farm to the end of follow-up or death. ${ }^{10}$

Because protection by endotoxincontaining dust seems to diminish over time after the cessation of exposure, the increased risk of lung cancer reported in the multicentre case-control study would presumably be an effect of other exposures, as shown by the association between occupational exposure to diesel exhaust and lung cancer which has recently been reported in the same set of cases and controls. ${ }^{11}$ Moreover in a European Community Respiratory Health Survey, in which job titles were categorised by an a priori constructed job exposure matrix into three classes of exposure, $80 \%$ of those exposed to organic dust were also exposed to mineral dusts and gases or fumes. ${ }^{12}$

The multicentre case-control study found an increased risk of lung cancer associated with ever being a farmer (OR 1.13,
$95 \%$ CI 1.04 to 1.22). The study did not take into account that there are two main categories of farmers - lifestock/dairy farmers and crop/orchard farmers. Livestock/dairy farmers but not crop/orchard farmers were protected against lung cancer according to the study in Italy. ${ }^{10}$

In this increasingly mobile world where workplaces have changed drastically, the traditional approach 'ever versus never' exposed could provide misleading results. ${ }^{13}$ To guide prevention and adjudicate compensation, the time-effect relation should be considered at the same time as the exposure-effect relationship. Otherwise the critical functions of epidemiology in the resolution of evidence-based medical controversies, which now act to protect the interests of both workers and employers, will become disconnected from reality.

\section{G Mastrangelo, ${ }^{1}$ R Rylander, ${ }^{2}$ L Cegolon, ${ }^{1,3}$ JH Lange ${ }^{4}$}

${ }^{1}$ Department of Environmental Medicine and Public Health, Padua University, Padua, Italy; ${ }^{2}$ BioFact Environmental Health Research Center, Lerum, Sweden; ${ }^{3}$ School of Public Health, Imperial College London, London, UK; ${ }^{4}$ Envirosafe Training and Consultants, Pittsburgh, Pennsylvania, USA

Correspondence to Dr L Cegolon, Department of Environmental Medicine and Public Health, Padua University, Padua, Veneto, Italy; I.cegolon@gmail.com

\section{Competing interests None.}

Provenance and peer review Not commissioned; internally peer reviewed.

Accepted 29 November 2011

Published Online First 11 January 2012

Thorax 2012;67:1112.

doi:10.1136/thoraxjnl-2011-201279

\section{REFERENCES}

1. Peters $\mathbf{S}$, Kromhout $\mathrm{H}$, Olsson $\mathrm{AC}$, et al. Occupational exposure to organic dust increases lung cancer risk in the general population. Thorax. Published Online First: 19 August 2011. doi:10.1136/ thoraxinl-2011-200716.

2. Lenters V, Basinas I, Beane-Freeman L, et al. Endotoxin exposure and lung cancer risk: a systematic review and meta-analysis of the published literature on agriculture and cotton textile workers. Cancer Causes Control 2010;21:523-55.

3. Henderson V, Enterline PE. An unusual mortality experience in cotton textile workers. J Occup Med 1973;15:717-19.

4. Rylander R. Environmental exposures with decreased risks for lung cancer? Int J Epidemiol 1990;19:S67-72.

5. Merchant J, Ortmeyer C. Mortality among employees of two cotton mills in North Carolina. Chest 1981;79(4 Suppl):6S-11S.

6. Hodgson J, Jones R. Mortality of workers in the British cotton industry in 1968-1984. Scand J Work Environ Health 1990;16:113-20.

7. Astrakianakis G, Seixas NS, Ray R, et al. Lung cancer risk among female textile workers exposed to endotoxin. J Nat/ Cancer Inst 2007;99:357-64.

8. Su HJ, Chen HL, Huang CF, et al. Airborne fungi and endotoxin concentrations in different areas within textile plants in Taiwan: a 3-year study. Environ Res 2002;89(1):58-65.
9. Mastrangelo G, Marzia V, Marcer G. Reduced lung cancer mortality in dairy farmers: is endotoxin exposure the key factor? Am J Ind Med 1996; 30:601-9

10. Mastrangelo G, Grange J, Fadda E, et al. Lung cancer risk effect of dairy farming and the consequence of removing occupational exposure. Am $J$ Epidemiol 2005;161:1037-46.

11. Olsson AC, Gustavsson $\mathrm{P}$, Kromhout $\mathrm{H}$, et al. Exposure to diesel motor exhaust and lung cancer risk in a pooled analysis from case-control studies in Europe and Canada. Am J Respir Crit Care Med 2011;183:941-8.

12. de Meer G, Kerkhof M, Kromhout $\mathrm{H}$, et al. Interaction of atopy and smoking on respiratory effects of occupational dust exposure: a general population-based study. Environ Health 2004;3:6

13. Guidotti TL. Occupational epidemiology. Occup Med (Lond) 2000;50:141-5. 